veins draining the hand causing swelling, induration of the skin, and eventual ulceration. Construction of a fistula linking the end of the vein to the side of the artery, with ligation of the venous branch draining the dorsum of the hand, may help avoid this complication.

Sustained venous hypertension on the skin capillaries of the canine hind limb causes an increase in the number and permeability of dermal capillaries with increased leakage of fibrinogen into the interstitium. ${ }^{2} \mathrm{~A}$ recent study on ulcer bearing skin of the leg in man showed layers of fibrin surrounding the dermal capillaries, and it has been postulated that extravascular fibrin stimulates tissue fibrosis and blocks the diffusion of oxygen to the overlying epidermis, resulting in ulceration. ${ }^{3}$ Histological examination of our patient's skin showed this capillary proliferation and the pericapillary fibrin that are the hallmark of venous hypertension.
We believe that this complication of arteriovenous fistulas is under reported and provides a unique opportunity to observe the effects of sustained venous hypertension on the skin in man similar to that seen in varicose ulceration of leg.

\section{References}

${ }^{1}$ Haimov M, Baez A, Neff M, Slifkin R. Complications of arteriovenous fistulas for haemodialysis. Arch Surg 1975;110:708-12.

2 Burnand KG, Clemenson G, Whimster I, Gount J, Browse NL. The effect of sustained venous hypertension on the skin capillaries of the canine hind limb. Br $\mathcal{F}$ Surg $1982 ; 69: 41-4$.

${ }^{3}$ Burnand KG, Whimster I, Naidoo A, Browse NL. Pericapillary fibrin in the ulcer-bearing skin of the leg: the cause of lipodermatosclerosis and venous ulceration. $\mathrm{Br} \mathrm{Med} \mathcal{F}$ 1982;285:1071-2.

(Accepted 6 fuly 1983)

\title{
Severe diabetic microangiopathy with normal glucose tolerance and pituitary infarction
}

\author{
R W BILOUS, R N POSTON, H KEEN, G C VIBERTI
}

\begin{abstract}
Blood glucose concentrations in a woman with severe retinopathy, nephropathy, and neuropathy were found to be within the normal range. A high random blood glucose concentration was recorded only once, six months before her initial presentation. At necropsy the anterior lobe of the pituitary gland showed old, extensive infarction.
\end{abstract}

Occult pituitary hypofunction may explain severe diabetic microangiopathy in patients with normal glucose tolerance.

\section{Introduction}

In 1936 Houssay described the ameliorating effect of hypophysectomy on hyperglycaemia and ketosis in dogs that had undergone pancreatectomy. ${ }^{1}$ Many studies on the influence of pituitary function on diabetes and its complications have since been reported. ${ }^{2}$ We report on a patient with severe retinopathy, nephropathy, and neuropathy in the absence of diabetes mellitus at the time of presentation. Postmortem examination showed infarction of the pituitary gland.

\section{Case report}

A 44 year old woman presented to this hospital in July 1978 complaining of blurred vision. In December 1977 she had been admitted

Unit for Metabolic Medicine, Guy's Hospital Medical School, London SE1 9RT

R W BILOUS, BSC, MRCP, research registrar

H KEEN, MD, FRCP, professor

G C VIBERTI, $M D$, senior research fellow

Department of Histopathology, Guy's Hospital Medical School R N POSTON, MRCPATH, lecturer

Correspondence and requests for reprints to: $\mathrm{Dr} R \mathrm{~W}$ Bilous, St Helier Hospital, Carshalton, Surrey. to another hospital with a superficial loin carbuncle, when glycosuria and a random blood glucose concentration of $17.6 \mathrm{mmol} / 1(317 \mathrm{mg} / 100$ $\mathrm{ml}$ ) had been recorded. She had also had heavy proteinuria, with a creatinine clearance of $52 \mathrm{ml} / \mathrm{min} / 1.73 \mathrm{~m}^{2}$. She had been given a single injection of 20 units of insulin before drainage of the abscess but thereafter had been treated with only dietary restriction. Blood glucose concentrations had returned promptly to the normal range. No formal glucose tolerance test had been performed.

On initial examination at this hospital she was obese $(90 \mathrm{~kg})$ with facial hirsutism and hypertension $(196 / 126 \mathrm{~mm} \mathrm{Hg})$. She had severe bilateral proliferative retinopathy with acuity reduced to $3 / 60$ on the right and $3 / 2$ on the left. Ankle reflexes and pin prick and vibration sensation were absent in both legs.

After fluoroscein angiography she underwent right laser photocoagulation, but a vitreous haemorrhage blinded her in November 1978. Investigations showed proteinuria of $2.5 \mathrm{~g} / 24 \mathrm{~h}$ and a glomerular filtration rate (edetic acid labelled with ${ }^{51} \mathrm{Cr}$ ) of $51 \mathrm{ml} / \mathrm{min} / 1.73 \mathrm{~m}^{2}$. A $75 \mathrm{~g}$ oral glucose tolerance test showed only impaired glucose tolerance (table). Her hypertension responded to beta blockers, and an intravenous urogram was normal. Left percutaneous renal biopsy in January 1979 confirmed diabetic glomerulosclerosis. Blood glucose concentrations on multiple occasions over this period never exceeded $6 \cdot 1 \mathrm{mmol} / 1(110 \mathrm{mg} / 100 \mathrm{ml})$. By June 1980 the glomerular filtration rate (edetic acid labelled with ${ }^{51} \mathrm{Cr}$ ) had declined to $13 \mathrm{ml} / \mathrm{min} / 1 \cdot 73$ $\mathrm{m}^{2}$; a second oral glucose tolerance test was performed, during which both plasma growth hormone and insulin concentrations were measured (table). Results of thyroid function tests, morning and evening plasma cortisol concentrations, and urinary free cortisol excretion were normal. She declined to undergo insulin stress test. By

Plasma glucose and growth hormone concentrations after $75 \mathrm{~g}$ oral glucose tolerance tests at presentation and two years later

\begin{tabular}{lccc}
\hline & & \multicolumn{2}{c}{ 16 June 1980 } \\
\cline { 3 - 4 } Time after glucose & $\begin{array}{c}\text { 23 August } 1978 \\
\text { Plasma glucose } \\
\text { load }\end{array}$ & $\begin{array}{c}\text { Plasma glucose } \\
(\mathrm{mmol} / \mathrm{l})\end{array}$ & $\begin{array}{c}\text { Growth hormone } \\
(\mathrm{mU} / \mathrm{l})\end{array}$ \\
\hline Fasting & $5 \cdot 9$ & $4 \cdot 1$ & 1 \\
$30 \mathrm{~min}$ & $8 \cdot 0$ & $5 \cdot 7$ & 1 \\
$60 \mathrm{~min}$ & $8 \cdot 0$ & $6 \cdot 9$ & 1 \\
$90 \mathrm{~min}$ & $8 \cdot 5$ & $6 \cdot 8$ & 1 \\
$120 \mathrm{~min}$ & $7 \cdot 3$ & $7 \cdot 2$ & 1 \\
$150 \mathrm{~min}$ & & $5 \cdot 2$ & 1 \\
$180 \mathrm{~min}$ & & $4 \cdot 3$ & 1 \\
$240 \mathrm{~min}$ & & $3 \cdot 9$ & 0 \\
$300 \mathrm{~min}$ & & &
\end{tabular}

Conversion: SI to traditional units-Glucose: $1 \mathrm{mmol} / 1 \approx 18 \mathrm{mg} / 100 \mathrm{ml}$. 
November 1980 her plasma urea concentration was $60 \cdot 2 \mathrm{mmol} / \mathrm{l}$ $(362 \mathrm{mg} / 100 \mathrm{ml}$ ) and she had peripheral gangrene in both feet. She died on 1 December.

Postmortem examination showed a laminated haematoma $12 \mathrm{~cm}$ in diameter around the left kidney, almost certainly due to the renal biopsy. Histologically there were classical Kimmelstiel-Wilson nodules and $60 \%$ hyalinised glomeruli in both kidneys, together with widespread arteriosclerosis. The anterior lobe of the pituitary gland showed old, extensive infarction.

\section{Discussion}

This patient had unequivocally diabetic hyperglycaemia only at the time of treatment of her loin carbuncle. No record of the retinal appearance was made then, but she had heavy proteinuria and a reduced creatinine clearance, almost certainly due to diabetic nephropathy. Quite possibly a long period of asymptomatic hyperglycaemia had preceded formation of the abscess. The return of normoglycaemia almost immediately postoperatively suggests, however, that such hyperglycaemia was probably mild, unless the pituitary infarction occurred at about the same time. The extent of infarction must have been incomplete physiologically, for despite low plasma growth hormone concentrations plasma cortisol concentrations were normal when measured seven months later. Pituitary infarction has been reported in $2 \%$ of diabetics coming to postmortem examination, ${ }^{3}$ and it was the regression of severe diabetic retinopathy in a diabetic who developed Sheehan's syndrome ${ }^{4}$ that led to the use of hypophysectomy as a treatment for this complication. Diabetic nephropathy was unaffected or worsened: the original patient died in renal failure. ${ }^{4}$ Our patient's retinopathy did not regress despite pituitary hypofunction, and renal function deteriorated relentlessly. Insulin requirements in patients who had undergone hypophysectomy dropped to between one third and one quarter of their preoperative dosage, ${ }^{2}$ illustrating the Houssay phenomenon ${ }^{1}$; our case suggests that in non-insulin dependent diabetics glucose tolerance may return to normal, resembling the metabolic improvement seen in patients with acromegaly who receive treatment.

It is now widely accepted that the development of diabetic microvascular complications is proportional to the severity and the duration of hyperglycaemia, although patients presenting in renal failure with biopsy appearances of diabetic glomerulosclerosis and normal glucose tolerance have been reported. ${ }^{5}$ None of these patients had retinopathy, and no data on pituitary function were reported. Occult pituitary hypofunction may possibly be present in such cases, and this would explain the apparent paradox of severe diabetic microangiopathy in the presence of normal glucose tolerance at the time of presentation.

RWB was supported by grant No I-AM-92200 from the National Institutes of Health, Bethesda, Maryland, USA.

\section{References}

${ }^{1}$ Houssay BA. Carbohydrate metabolism. N Engl f Med 1936;214:971-86.

2 Luft R. The use of hypophysectomy in juvenile diabetes mellitus with vascular complications. Diabetes 1962;11:461-2.

${ }^{3}$ Brennan CF, Malone RGS, Weaver JA. Pituitary necrosis in diabetes mellitus. Lancet 1956;ii:12-6.

4 Poulsen JE. Diabetes and anterior pituitary insufficiency. Final course and post mortem study of a diabetic patient with Sheehan's syndrome. Diabetes 1966;15:73-7.

${ }^{5}$ Harrington JT, Garella S, Stilmant MM, Chazan JA. Renal failure as the initial manifestation of diabetes mellitus. Arch Intern Med 1973;132. 249-51.

(Accepted 28 fune 1983)

\title{
Effects of pirbuterol and sodium nitroprusside on pulmonary haemodynamics in hypoxic cor pulmonale
}

\author{
W MACNEE，C G WATHEN，W J HANNAN，D C FLENLEY，A L MUIR
}

\begin{abstract}
The acute haemodynamic effects of oral pirbuterol (a beta-agonist) were contrasted with those of sodium nitroprusside, a vasodilator, in six patients with hypoxic chronic bronchitis and emphysema. Sodium nitroprusside (1-5 $\mathrm{mg} / \mathrm{kg}$ intravenously) reduced mean pulmonary arterial pressure and total pulmonary vascular resistance significantly $(p<0.01)$ without change in cardiac output or right ventricular ejection fraction, measured by radionuclide ventriculography. Oral pirbuterol $(22.5 \mathrm{mg})$ produced a greater reduction in total pulmonary vascular resistance than sodium nitroprus-
\end{abstract}

University of Edinburgh, Edinburgh

W MACNEE, MB, MRCP, senior registrar, department of respiratory medicine C G WATHEN, MB, MRCP, clinical lecturer, department of medicine W J HANNAN, PHD, senior physicist, department of medical physics

D C FLENLEY, PHD, FRCPED, professor, department of respiratory medicine A L MUIR, MD, FRCPED, reader, department of medicine

Correspondence to: $\mathrm{Dr}$ MacNee, Department of Respiratory Medicine, City Hospital, Edinburgh EH10 5SB. side, largely as a result of increasing cardiac output. Right ventricular ejection fraction also increased significantly after pirbuterol $(p<0.01)$. Pirbuterol in a lower dosage (15 $\mathrm{mg}$ by mouth) in six further patients with hypoxic chronic bronchitis and emphysema produced similar changes in total pulmonary vascular resistance and right ventricular ejection fraction. Nine of the patients who were studied acutely thereafter received pirbuterol $15 \mathrm{mg}$ thrice daily for six weeks, which produced a significant fall in systolic pulmonary arterial pressure and a rise in right ventricular ejection fraction $(p<0.01)$, without a significant fall in arterial oxygen tension.

Pirbuterol acts as a vasodilator on the pulmonary circulation in these patients and may in addition improve right ventricular performance by an inotropic action.

\section{Introduction}

The association between the arterial hypoxaemia of chronic lung diseases and the development of pulmonary hypertension is well known, ${ }^{1-6}$ the hypoxaemia producing pulmonary vasoconstriction by a mechanism as yet unknown. Although the pro- 